\section{Science university debuts}

\section{Hong Kong}

THE Hong Kong University of Science and Technology, the British territory's third fully fledged university and the first devoted specifically to the study of scientific topics, opened its doors last week. The school is expected to play a significant role in the economic transition of Hong Kong "from a low-tech, labourintensive economy to a high-tech information-based society", in the words of the university vice chancellor, Woo Chia-wei.

With a population approaching 6 million squeezed into a space of scarcely more than ten hectares with few natural resources, Hong Kong has had to live on its wits. Over the past three decades, it has done so in a low-technology way, using cheap labour to manufacture electronic components, assemble consumer electronic devices and manufacture garments.

Now, however, the situation is changing. Asian nations such as Malaysia and Thailand are moving in on Hong Kong's low-technology markets, while the other 'little dragons' - Singapore, South Korea and Taiwan - are moving on to more sophisticated forms of technology. To survive, Hong Kong's companies must upgrade their technology.

The government already pays for research and development at two public universities and two polytechnics, but the universities are too diverse and the polytechnics not well enough accepted academically to provide leadership in Hong Kong's world of technology. The new university promises to fill the vacuum.

It will do so in large measure by encouraging postgraduates, who now make up fewer than 10 per cent of students at Hong Kong's universities. The new uni- versity has about 140 postgraduates in its first group of 700 students, and it plans to increase the number to 30 per cent.

The emphasis on postgraduate education should help Hong Kong's economy in two ways. First, it will provide a local alternative for talented science graduates who in the past have felt forced to travel overseas to continue their studies. Too often they never return. Postgraduate studies will also provide a link to the local industrial community through joint research and development projects.

Located in a seaside setting in Hong Kong's New Territories, the new university has four schools: science, engineering, business and management, and humanities and social sciences. Students in science and engineering can read for undergraduate and higher degrees in biochemistry, biology, chemistry, mathematics, physics, computer science, and electrical and electronic engineering. Postgraduate studies in mechanical engineering and civil and structural engineering are now available; those subjects will be extended to undergraduates next year, and chemical engineering and industrial and mechanical engineering will be added in 1993.

The university, which can now accommodate 2,000 full-time students, intends to enrol 1,000 undergraduates and 250 graduate students in its second academic year, beginning in October 1992. A second phase of construction, due to be completed in 1993, will permit a student population of about 7,000 by the 1993-94 school year, while a third phase will bring the institution up to its planned capacity of 10,000 students by $1995-96$.

Peter Gwynne

\section{Columbus delayed}

\section{London}

Although the US Congress has agreed to grant the full 1992 presidential budget request for the space station Freedom $(\mathrm{Na}$ ture 353,372 ; 3 October 1991), the controversial international project now faces another budgetary hiccup. Next month, ministers from the 13 nations of the European Space Agency (ESA) are expected to give their continued backing to the Columbus project - which includes ESA's contribution to the station - only if elements of the project are delayed in order to reduce costs over the next few years.

One such element will be a free-flying unmanned microgravity laboratory designed to orbit with the station. Fredrik Engstrom, who is directing ESA's contribution to the space station, says the launch of the free flyer will be delayed by two years, to 2003. (When first conceived, it was to have been launched in 1999 , but previous delays have already shifted this to 2001.) Engstrom says there will now be no "hard-core development work" on the free flyer for the next three years. The precise amount of money saved by the delay has not been calculated, he says, but one thing is sure: despite the short-term savings, any launch delay will increase the total cost of the Columbus project.

ESA's manned laboratory, which will be bolted onto the main station, should still be launched in 1998, as planned. P.A.

BIOMEDICAL RESEARCH

\section{Rockefeller loses one}

\section{Washington}

Nobec laureate Gerald Edelman and the Neurosciences Institute that he directs will leave Rockefeller University for greener pastures at the Scripps Research Institute, Edelman announced early this week. Scripps offered the Institute a new \$7-million building, something Edelman describes as a "magnificent opportunity" that he could not turn down. Critics of Rockefeller president David Baltimore note that Edelman is the second prominent Rockefeller scientist to leave in as many months, following diabetes researcher Anthony Cerami (see Nature 352, 463; 8 August 1991). But Edelman plays down speculation of a link. "The old Rockefeller system was one I very much admired," he says. "It has changed since then, but that in no way influenced my decision." Scripps, meanwhile, can add Edelman to its quickly growing list of notable recruits to the southern California research campus. With funding that has more than doubled in the last five years to a total of $\$ 85$ million, Scripps has in the last year snared such prominent researchers as chemists Barry Sharpless and K.C. Nicolaou, molecular geneticist Sydney Brenner and plant biologist Roger Beachy. nese pharmaceutical companies already based in Tsukuba, as well as Upjohn of the million laboratory with 170 researchers in 988, and ICI of the United Kingdom.

centre opened five days after Glaxo's. The $¥ 5,400$-million centre is expected to have about 100 researchers when recruitment is complete. The US semiconductor manuTsukuba. Intel's laboratory concentrates on development of products fairly close to market, but the TI institute - like the fundamental NEC research institute next door - will concentrate on more basic research and in particular on nanotechnology, a topic that is rapidly catching the interest of Japan's industrial research community.
David Swinbanks 